\title{
ASPECTOS DE INOVAÇÃO E DE REDES QUE AFETAM A IMAGEM DA MARCA: O CASO HARLEY-DAVIDSON E BUELL
}

\author{
Celso Augusto Rimoli \\ celso.rimoli@gmail.com \\ Universidade Paulista - São Paulo, SP / Brasil \\ Léo Eduardo Pastori Noronha \\ leo.eduardo@ig.com.br \\ Universidade Paulista - São Paulo, SP / Brasil \\ Francisco Antonio Serralvo \\ serralvo@pucsp.br \\ Pontifícia Universidade Católica de São Paulo - São Paulo, SP / Brasil
}

Recebido em 10/07/2012

Aprovado em 21/02/2013

Disponibilizado em 01/08/2013

Avaliado pelo sistema double blind review

Revista Eletrônica de Administração

Editor: Luís Felipe Nascimento

ISSN 1413-2311 (versão on-line)

Editada pela Escola de Administração da Universidade Federal do Rio Grande do Sul.

Periodicidade: Quadrimestral

Sistema requerido: Adobe Acrobat Reader.

\section{RESUMO}

Entre as diversas tendências que impactam atualmente o mundo dos negócios duas se destacam: a alta taxa de inovação e o fato de a sociedade se organizar cada vez mais em redes. Em complementação, alguns autores ressaltam que, em uma sociedade como essa os aspectos relacionados à marca tendem a ser mais relevantes para a diferenciação competitiva da oferta das empresas do que aqueles ligados à qualidade do produto. Nesse contexto, o objetivo deste artigo é analisar como aspectos de inovação e de redes afetam a imagem de duas marcas globais de uma mesma empresa no Brasil. Trata-se de uma das primeiras investigações empíricas das contribuições de um ensaio teórico e por isso o trabalho envolveu a realização de uma pesquisa exploratório-descritiva que empregou a estratégia de pesquisa estudo de casos. Foram analisadas as marcas Harley-Davidson e Buell, de motocicletas fabricadas pela empresa Harley-Davidson Motor Company em função de elas atenderem aos requisitos implícitos no objetivo. As análises realizadas permitiram verificar uma grande convergência e aderência de resultados entre a parte conceitual, as informações secundárias e as informações primárias coletadas, reforçando as conclusões e permitindo a formulação de sugestões para pesquisas futuras.

Palavras-chave: imagem da marca; identidade da marca; inovação, redes de negócio. 
Aspectos de inovação e de redes que afetam a imagem da marca: o caso Harley-Davidson e Buell

\title{
INNOVATION AND NETWORK ASPECTS AFFECTING BRAND IMAGE: THE CASE OF HARKEY-DAVIDOSN AND BUELL
}

\begin{abstract}
Among the many trends impacting the business world nowadays two have become most prominent: the high tax of innovation and the fact that society is more and more organizing itself as networks. In addition, some authors pose that in such a society aspects relating to brand management tend to be more relevant for competitive differentiation than those relating to the quality of products. In this context, this paper aims at analyzing how aspects of innovation and networks affect the image of two global brands from the same company in Brazil. This is one of the first empirical investigations on the contributions of a theoretical essay and because of that the work is characterized as an exploratory and descriptive research that employed the case study research strategy. The brands chosen for analysis were HarleyDavidson and Buell, from the motorcycles produced by the Harley-Davidson Motor Company, because they conform to the requirements implicit in the objective. The analysis performed revealed great convergence and adherence between concepts and secondary and primary data collection, reinforcing the conclusions and allowing the formulation of suggestions for future research.
\end{abstract}

Keywords: brand image; brand identity; innovation; business networks.

\section{INTRODUÇÃO}

Este artigo constitui um dos primeiros esforços de verificação empírica das contribuições teóricas formuladas no ensaio desenvolvido por Rimoli e Giglio (2009), que traz uma revisão ampla da literatura sobre as áreas de inovação, redes e marketing. $\mathrm{O}$ ensaio foi escrito com base na assertiva de que marketing é limitado tanto em teoria quanto em gestão quando se lida com inovações radicais no âmbito de sua rede de relacionamentos. $\mathrm{O}$ teor das contribuições se refere ao modo como as inovações, produtos e mensagens se propagam nas redes sociais e de negócios, consubstanciado nas ideias que seguem. O fortalecimento da confiança e da cooperação entre os atores de uma rede social ou de negócios tende a aumentar a velocidade de difusão de inovações, produtos e mensagens por ela. Entretanto a influência social cria barreiras no inicio do processo de difusão, mas o acelera a partir de certo ponto de difusão; e o fato de não se poder garantir o caráter positivo ou negativo da difusão nas redes agrega credibilidade a esse processo.

Sobre inovação, Mariano (2004) ressalta que no ambiente atual globalizado a concorrência se torna cada vez mais acirrada e as organizações precisam conquistar e manter vantagem competitiva pela geração e implementação de novas ideias (tecnologia, design, etc.) em processos, produtos e serviços. E quanto às redes, vários autores (CASTELLS, 2000; KLEIN, 2003; OZCAN, 2004) reconhecem o advento de uma sociedade em redes, na qual a troca REAd I Porto Alegre - Edição 75 - N 2 - maio/agosto 2013 - p. 401-432 
entre as pessoas e as organizações - os atores da rede social - é cada vez mais relacional e, portanto atributos como confiança, comprometimento e cooperação são fundamentais. Esses atores envolvem fornecedores, universidades, institutos de pesquisa, governo, distribuidores, canais de vendas, formadores de opinião, a mídia e consumidores, entre outros (NUNES; HAIGH, 2003).

Neste trabalho procurou-se particularizar essas contribuições genéricas ao modo como a inovação e as redes influenciam e condicionam as marcas globais. Nesse sentido, Ruão e Fanhagmer (2000) afirmam que a intensificação da tecnologia e da inovação em uma sociedade cada vez mais interconectada em redes globais vem tornando os aspectos relacionados à marca mais necessários à diferenciação competitiva da oferta das empresas do que os aspectos ligados à qualidade do produto. Os autores ressaltam dois pontos específicos: que se está mudando de um mercado de produtos para um mercado de marcas e também que uma das dimensões mais importantes dessa nova realidade é a imagem da marca. Isso porque ela traduz o conjunto de significados que os consumidores constroem a partir dos atributos das marcas que as empresas comunicam a eles.

Nesse contexto de marcas globais que alcançam importância maior que os produtos e empresas em uma sociedade intensa em inovação e que cada vez mais opera segundo redes de relações, se insere o objetivo deste trabalho: analisar como aspectos de inovação e de redes de podem afetar a construção da imagem das marcas globais.

Foi necessário encontrar objetos de estudo compatíveis com esse questionamento e, após extensa busca, optou-se por examinar as marcas Harley-Davidson e Buell, da empresa Harley-Davidson Motor Company. A escolha recaiu sobre essas marcas porque uma delas apresenta aspectos e características inovadores (Buell), ao passo que a outra (HD) traz aspectos de redes, como é o caso do Harley owners group (HOG).

Para a execução do trabalho considerou-se adequada uma investigação em profundidade por meio da estratégia de pesquisa estudo de caso (YIN, 2005). O objetivo proposto e o exame de informações secundárias a respeito das duas marcas, apresentadas adiante, conduziram à elaboração das seguintes proposições aplicadas a elas, nos moldes desse autor.

1. Aspectos de inovação afetam com maior intensidade a imagem da marca Buell;

2. Aspectos de redes de negócios afetam com maior intensidade a imagem da marca HD; e

3. A inovação teve grande importância em um dado contexto histórico da marca HD o que favorece a força da marca até os dias atuais. 
Aspectos de inovação e de redes que afetam a imagem da marca: o caso Harley-Davidson e Buell

Em sua estrutura, o trabalho traz, na Seção 2, a revisão da literatura, que compreende conhecimentos sobre inovação, redes e marcas, constituindo o corpo teórico do trabalho. $\mathrm{Na}$ Seção 3 são desenvolvidas as considerações metodológicas envolvidas na pesquisa. Na Seção 4 são apresentados e analisados os resultados das informações coletadas e por fim, na Seção 5, há as conclusões, as limitações e as sugestões para pesquisas futuras.

\section{REVISÃO DA LITERATURA}

Os itens 2.1 e 2.2 da revisão - sobre inovação e redes - se baseiam e adaptam o conteúdo do trabalho de Rimoli e Giglio (2009) à temática deste artigo e na Seção 2.3 se discorre sobre identidade e imagem das marcas, terminando com uma conclusão conceitual na Seção 2.4.

\subsection{Inovação}

O termo inovação tem sido largamente conceituado ao longo do tempo, sendo que Mariano (2004) explica que esse conceito migrou de uma visão puramente técnica para a aplicação de qualquer conhecimento que agregue valor ao desenvolvimento e comercialização de produtos, serviços e à gestão de organizações. Moreira e Queiroz (2007) afirmam que diversos autores vêm propondo classificações de inovações de maneiras variadas, como tecnológicas, organizacionais, de produto (ou serviço) e de processo, radicais e incrementais, entre outras. Nessa linha, o Manual de Oslo (2005) sistematiza e recomenda os seguintes tipos de inovação: de produto, de processo, organizacional e de marketing. Entretanto, o último tipo mencionado - radicais e incrementais - de certa forma precede e contêm os demais, pois é possível se ter inovações incrementais e radicais em produtos, em processos, em organizações, etc.

Lemos (1999) afirma que as inovações incrementais envolvem aperfeiçoamentos em produtos, processos e métodos existentes, caracterizando mudanças evolucionárias em oposição às revolucionárias. Os produtos que as incorporam são substitutos próximos uns dos outros e se localizam mais ao final da cadeia de fornecimento, próximos aos consumidores finais. De acordo com Mohr, Sengupta e Slater (2005) essas inovações fornecem uma idéia clara sobre os aperfeiçoamentos necessários ou desejados em processos, produtos e serviços, sendo fácil para os consumidores fornecerem essas informações às empresas produtoras, caracterizando uma situação conhecida por customer pull.

Já as inovações radicais envolvem a utilização de invenções ou de resultados de laboratório em busca de aplicações comerciais lucrativas. Lemos (1999) pondera que as 
inovações radicais geralmente se desdobram no desenvolvimento e no lançamento de produtos ou processos inéditos, ou em uma forma totalmente nova de organizar a produção. Em geral as inovações radicais ocorrem nos níveis iniciais da cadeia de fornecimento, próximas aos fornecedores de insumos e podem afetar substancialmente o processo de fabricação do respectivo produto. Podem assim representar uma ruptura estrutural com o padrão tecnológico vigente, dando origem a novas organizações, setores e mercados e, por essas razões, caracterizam situações conhecidas como technology push.

Nessa linha, Christensen (2000) ressalta outra característica importante envolvendo inovações incrementais e radicais. Ele coloca que as primeiras são muito mais abundantes que as últimas e disso resulta que as empresas corretamente aplicam os preceitos das melhores práticas de marketing estabelecidas junto a seus produtos líderes de mercado. Mas é preciso estar atento ao surgimento de inovações radicais que caracterizem ruptura com os padrões tecnológicos e mercadológicos vigentes. Freqüentemente, os fabricantes de produtos líderes ou não podem, ou não querem incorporar inovações radicais a seus produtos e processos na fase inicial, o que é feito apenas por um pequeno grupo presente em nichos inovadores. Posteriormente a nova tecnologia e os produtos que a utilizam podem evoluir e conquistar o mercado principal, substituindo a antiga e tornando obsoletos os produtos que antes lideravam o mercado. Em consequência, quando surge uma inovação radical relacionada a uma tecnologia de ruptura, as empresas líderes de mercado podem ter suas posições ameaçadas, como ocorreu com as câmeras fotográficas digitais em relação às câmeras com filmes.

Como resultado desses fatos, John, Weiss e Dutta, (1999), assim como Mohr, Sengupta e Slater (2005), argumentam que marketing precisa ser adaptado e modificado para que se possa lidar eficazmente com um ambiente empresarial complexo. Assim, quanto mais presentes em um setor forem as inovações incrementais, mais convencional a abordagem de marketing deve ser. No outro extremo, quanto mais as empresas lidarem com inovações radicais em sua oferta ao mercado, mais as ferramentas de marketing devem ser adaptadas a essas condições. Conforme Hills e Sarin (2003), quanto maior for o grau de inovação envolvido em produtos e serviços, mais difícil será entender as necessidades dos consumidores por métodos tradicionais, como pesquisas quantitativas.

Para os efeitos deste trabalho, as inovações são analisadas sob dois aspectos: conforme o grau de novidade associado a cada inovação (se ela é mais radical ou incremental); e também conforme a tipologia do Manual de Oslo (2005). Assim, a Figura 1 ilustra a classificação sob 
Aspectos de inovação e de redes que afetam a imagem da marca: o caso Harley-Davidson e Buell

essas duas dimensões, relacionando os vários tipos de inovação apresentados a seu grau de novidade e serviu como base para a coleta de dados na parte de inovação.

\begin{tabular}{|c|c|c|c|c|c|c|c|c|c|c|}
\hline \multirow{2}{*}{$\begin{array}{l}\text { Tipos de } \\
\text { inovação } \\
\text { Produto }\end{array}$} & \multicolumn{8}{|c|}{ Radical } & \multicolumn{2}{|c|}{ Incremental } \\
\hline & 1 & 2 & 3 & 4 & 5 & 6 & 7 & 8 & 9 & 10 \\
\hline Processo & 1 & 2 & 3 & 4 & 5 & 6 & 7 & 8 & 9 & 10 \\
\hline Organizacional & 1 & 2 & 3 & 4 & 5 & 6 & 7 & 8 & 9 & 10 \\
\hline Marketing & 1 & 2 & 3 & 4 & 5 & 6 & 7 & 8 & 9 & 10 \\
\hline
\end{tabular}

Figura 1 - Tipos de inovação segundo o grau de novidade associado Fonte: os autores.

\subsection{Redes de negócios}

Para entender as teorias que caracterizam as redes é necessário apresentar seus conceitos centrais. Conforme Kempe, Kleinberg e Tardos (2005), as redes constituem uma representação das relações e interações entre indivíduos e grupos, desempenhando um papel importante como meio de difusão de informação, de idéias, de influências, de produtos e de serviços. Ebers e Jarillo (1997) definem redes como um conjunto de conexões denominadas nós. O nó é a unidade básica das redes e representa o encontro de atores como fornecedores, clientes, concorrentes, instituições de apoio, governo, institutos de pesquisa, imprensa, etc. Conforme Hakansson e Snehota (1995), a estrutura de um nó compreende três itens: atores, recursos e atividades. Entre os recursos mais importantes alguns autores (GULATI; GARGIULO, 1999; UZZI, 1997) têm destacado o embeddedness, cuja ideia básica é o entrelaçamento social e econômico entre os atores, que simultaneamente impõe limites de comportamento e desenvolve outros recursos, entre eles, como o capital social. O embeddedness existe e se desenvolve a partir de atributos como confiança, comprometimento, lealdade, interdependência e coesão. Desse modo, os conceitos de nó e de embeddedness sugerem que uma empresa não pode (e não consegue) privilegiar uma relação em detrimento das outras. Ou ela está comprometida com a rede, ou seu elo é tão fraco que ela não vai obter vantagens por estar na rede.

Segundo Tichy, Tushman e Fombrun (1979), a abordagem de redes sociais concebe as organizações na sociedade como um sistema de objetos (pessoas, grupos ou empresas) unidos por relacionamentos variados. Nem todos os objetos estão diretamente ligados, mas alguns o estão por múltiplos relacionamentos. Salancik (1995) coloca que as redes são construídas a partir de interações entre indivíduos e organizações que permitem o surgimento de REAd I Porto Alegre - Edição 75 - Nº 2 - maio/agosto 2013 - p. 401-432 
determinadas estruturas. Nelas é importante considerar se há atores com maior número de relacionamentos do que outros (centralidade), se cada membro da rede pode ser contatado por todos os outros (densidade), o tamanho da rede, a existência de grupos mais fechados dentro da rede (cliques) e se alguns atores interagem sempre com os mesmos indivíduos. Esse autor também afirma que uma teoria de rede consistente com os estudos organizacionais deveria explicar por que determinados atores são mais centrais do que outros, se em razão de existir maior conectividade entre eles, ou devido à equivalência estrutural, que contribuiria para a formação de uma estratégia coletiva da rede. O fluxo de informação é o fato central na organização da estrutura social e possibilita formas antes inexistentes de ligações entre pessoas e organizações.

Desse modo a corrente social de redes busca fundamentação e investiga os campos político, histórico, cultural e social para entender as redes de empresas. Por exemplo, em seus trabalhos, Piore e Sobel (1984) e Putnan (1996) revelam interesse por questões relacionadas à confiança, à identidade cultural, à interação social, às prerrogativas históricas e à territorialidade dos fenômenos. Para tanto se deve considerar que o sucesso das redes está na gerência de conflitos e interesses individuais. Os mecanismos de controle desse gerenciamento incluem desde medidas mais rígidas, como no caso da existência de um centralizador da rede, até dinâmicas extremamente democráticas de decisões.

Nesse contexto, conforme ressaltaram Castells (2000) e Ozcan (2004), há um processo de transformação de uma sociedade baseada em mercado para uma sociedade em redes, na qual os atores migram de posições e decisões individuais para outras de interdependência e cooperação de acordo com suas conexões na rede. Tal transformação encerra uma lógica diferente nos processos de trocas realizados, apresentando as transações em bases relacionais como alternativa às transações posicionais ou discretas (CASTELLS, 2000; DWYER; SCHURR; OH, 1987; KLEIN, 2003; OZCAN, 2004).

O próximo tópico examina aspectos de identidade e de imagem de marcas, que envolvem essas duas lógicas de trocas - posicional e relacional - e levam em conta também as questões de inovação discutidas antes.

\subsection{Identidade e imagem da marca}

Aaker (1996), Kapferer (1991) e Ruão e Farhangmer (2000), entre outros autores descreveram os componentes da marca, identificando elementos diversos, em maior ou menor 
Aspectos de inovação e de redes que afetam a imagem da marca: o caso Harley-Davidson e Buell

detalhe. Para alcançar o objetivo declarado na introdução, o foco deste trabalho foi dirigido aos seguintes elementos: identidade, comunicação e imagem da marca.

As marcas possuem identidade, isto é, uma coleção de características que as definem, como uma essência ou um código interno que tem sido largamente debatido entre pesquisadores, sobretudo a partir da década de 1990. Parece haver um relativo consenso em considerar a identidade como um conjunto de atributos que uma organização gostaria de emitir a seus públicos (AAKER, 1996; KAPFERER, 1991; SEGUELA, 1982).

O significado de uma marca junto a seus públicos-alvos é definido por sua imagem e é necessário que o gestor desenvolva estímulos que provoquem associações positivas a ela (AAKER, 1996). O mesmo autor afirma que a imagem da marca é entendida principalmente como o resultado de sua identidade, representando as associações únicas que foram definidas pelo gestor da marca. Nota-se a existência de uma relação de causa e efeito - ainda que sujeita a variáveis intervenientes - entre esses dois conceitos, sendo a imagem uma variável dependente da identidade da marca.

Por outro lado são poucas as empresas que conhecem adequadamente suas marcas e quais são as qualidades que as singularizam no mercado. Isso resulta no aumento da importância de as marcas se comunicarem diretamente com seus públicos-alvos para além das campanhas dos produtos a que estão vinculadas (KAPFERER, 1992).

Danes et al. (2010) observam que existe concordância sobre a ideia de que a imagem da marca é uma construção mental que os públicos-alvos formam baseados em suas conexões, experiências e associações com ela. Tal construção resulta dos esforços gerenciais da organização em erigir a identidade da marca. Keller (2008) afirma que o propósito da identidade é dar à marca uma estrutura do que deve estar na mente dos consumidores. Complementarmente Rindell e Strandvik (2010) afirmam que é o mercado que constrói a reputação (imagem) da marca, o que resulta das ações de comunicação no mercado.

A Figura 2 esquematiza a construção da marca desde sua identidade, que é comunicada aos públicos-alvos e assim se define sua imagem, mas concorrem para isso também as outras fontes e uma parcela de ruído, elementos detalhados em seguida. 


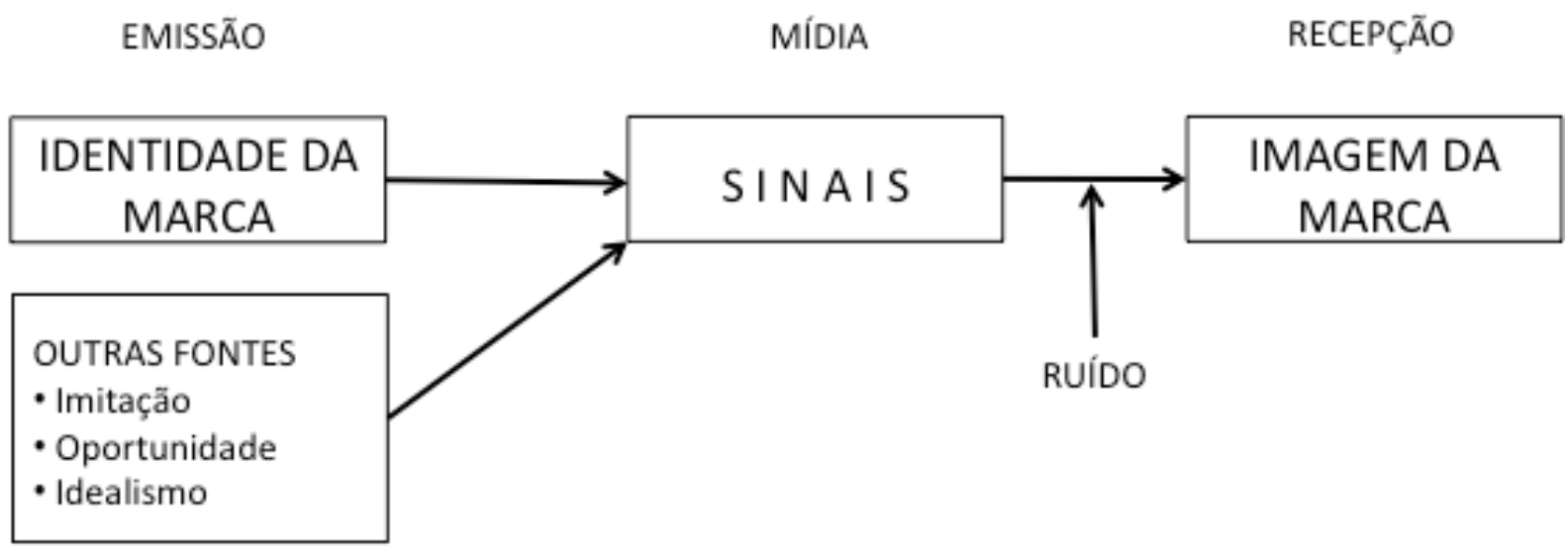

Figura 2 - Identidade e Imagem da Marca Fonte: Kapferer (1992, p. 38).

O primeiro elemento do processo é a identidade da marca que, para Kapferer (2003) é um conjunto de atributos definidos em seis dimensões, indicadas entre parêntesis. São eles: qualidades objetivas (ambiente físico) e subjetivas (personalidade); desenvolvem-se em um contexto (cultura) que lhes dão substância e força na convivência com os públicos-alvos (relação); e são percebidos de forma particular pelos públicos-alvos (reflexo), gerando neles sentimentos internos específicos (mentalização).

Já Aaker (1996) define identidade como o conjunto de associações que dão sentido, significado e finalidade a determinada marca, características peculiares e intransferíveis. Para esse autor identidade representa aquilo que a marca pretende realizar e implica uma promessa feita aos clientes pelos membros da organização segundo quatro dimensões: produto, organização, pessoa e símbolo, conforme o Quadro 1.

Quadro 1 - Imagem da Marca segundo Aaker

\begin{tabular}{|c|c|c|c|}
\hline $\begin{array}{c}\text { A marca como } \\
\text { produto }\end{array}$ & $\begin{array}{c}\text { A marca como } \\
\text { organização }\end{array}$ & $\begin{array}{c}\text { A marca como } \\
\text { pessoa }\end{array}$ & $\begin{array}{c}\text { A marca como } \\
\text { símbolo }\end{array}$ \\
\hline $\begin{array}{l}\text { 1. Escopo do produto } \\
\text { 2. Atributos do } \\
\text { produlo } \\
\text { 3. Qualidade/Valor } \\
\text { 4. Usos } \\
\text { 5. Usuários } \\
\text { 6. Pais de origem }\end{array}$ & $\begin{array}{l}\text { 7. Atributos da } \\
\text { organizaçào (p. ex: } \\
\text { inuvaçà, } \\
\text { preocupaçào de } \\
\text { consumidores, } \\
\text { confiabilidade) } \\
\text { 8. Local versus } \\
\text { global }\end{array}$ & $\begin{array}{l}\text { 9. Personalicade (p. } \\
\text { ex: genuina, } \\
\text { enérgica, robustd) } \\
\text { 10. Relacionamento } \\
\text { cliente/marca }\end{array}$ & $\begin{array}{l}\text { 11. Imagem e } \\
\text { metáforas visuais } \\
\text { 12. Herançuda da } \\
\text { marca }\end{array}$ \\
\hline
\end{tabular}

Fonte: Adaptado de Aaker (1996).

REAd I Porto Alegre - Edição 75 - N 2 - maio/agosto 2013 - p. 401-432 
Aspectos de inovação e de redes que afetam a imagem da marca: o caso Harley-Davidson e Buell

As associações da identidade da marca ao produto estão diretamente relacionadas a seu desempenho e aceitação (prestígio) no mercado. Já as associações relacionadas à organização dizem respeito aos atributos da organização em si e não a seus produtos (AAKER, 1996). Mas os dois tipos de associação se complementam, pois os atributos organizacionais em geral funcionam como patrocinadores e garantidores do bom desempenho do produto e da marca (BENGTSSON et al., 2010).

No plano da marca como pessoa, os pontos que se destacam são a personalidade e o relacionamento, além do envolvimento, que se estabelecem entre os públicos-alvos e a marca. Guthrie e Kim (2009, p. 115), afirmam que o "envolvimento do consumidor é um estado motivacional que pode ser usado para entender as atitudes dos consumidores em relação à marca”. Além disso, o envolvimento pode ser utilizado para mensurar o interesse e o significado da marca para os públicos-alvos.

Por fim, a marca como símbolo pode proporcionar coesão e densidade para o conjunto de associações, facilitando o reconhecimento e a recordação por parte do públicos-alvos (BERNSTEIN, 2009).

Tanto na proposição de Kapferer (2004, 2003, 1992, e 1991) quanto na de Aaker (1996), as dimensões descritas por meio dos atributos que as compõem, caracterizam o que se denominou valor da marca, o que vai muito além do produto e suas características físicas, por trazerem credibilidade à oferta da empresa. Para ser eficaz, a identidade de marca precisa ressoar com clientes e demais stakeholders, diferenciando-se das concorrentes e representando o que a organização pode fazer e fará ao longo do tempo.

O segundo elemento da Figura 2, mídia, aborda a questão da difusão, que é crucial, uma vez que a marca só existe na medida em que é reconhecida pelo consumidor. A fim de que a identidade física e psicológica se concretize, é preciso que a marca seja apresentada aos públicos-alvos e aceita por eles. A área de marketing deve concentrar esforços não só na definição clara e coerente de uma identidade forte para as marcas, mas igualmente em desenvolver um composto de comunicação capaz de difundi-la. Como afirma Kapferer (1991), a marca, por enunciar produtos e serviços em meio a outros valores, depende da comunicação para ser conhecida e reconhecida. Desse modo a comunicação de marca é o processo de transferência que conduz a identidade à imagem de marca.

E quanto ao terceiro elemento da Figura 2, Ruão e Farhangmer (2000) afirmam que o conceito de imagem da marca tem evoluído bastante desde os anos 1950, quando foi introduzido no estudo do comportamento do consumidor. Nessa perspectiva se define imagem 
da marca como o resultado da síntese mental, feita pelos públicos-alvos, de todos os sinais emitidos pela marca, como nome, símbolos visuais, produtos, anúncios publicitários, patrocínios etc. Para Koubaa (2008) a imagem da marca advém da configuração mental e do processo analítico dos indivíduos, sendo que sua formação está sujeita a fatores externos e internos a eles.

A construção da imagem de qualquer marca pressupõe interpretação e decodificação por parte dos receptores do conjunto de sinais emitidos por ela (KOTLER e KELLER, 2006). Nos processos de decodificação o receptor contribui fortemente para o resultado final, ou seja, há uma parte da construção da imagem da marca que não depende do estímulo realizado, mas do processo de conceituação de quem o recebe. O resultado é a distinção entre a identidade que a marca projeta dela própria ao mercado - e a imagem percebida por esse último - aquela que os públicos-alvos constroem a partir dos contatos que estabelecem com a marca. Por isso a gestão de marcas será tanto mais efetiva quanto mais puder diminuir as diferenças entre o que a empresa emite da marca (identidade) e o que seus públicos apreendem (imagem).

Assim, no final do processo de difusão, tem-se a imagem da marca, que para Barich e Kotler (1991, p. 95), "é a soma das crenças, atitudes e impressões que uma pessoa ou um grupo tem sobre um objeto... As impressões podem ser verdadeiras ou falsas, reais ou imaginárias. Certo ou errado, a imagem guia e molda o comportamento dos indivíduos".

Rajagopal (2009, p. 61) afirma que "os consumidores têm apenas uma imagem única da marca, que é criada pelos efeitos dos ativos da marca, tais como: nome, tradição, embalagem, publicidade, promoção, preço, aceitação no mercado, disciplina da força de vendas, satisfação do consumidor, níveis de identidade etc."

Em suma, o ponto de vista atualmente dominante na literatura é que as estratégias de gestão de marcas devem ser consistentes ao longo do tempo e do espaço no sentido de produzirem associações mais favoráveis à marca (KELLER, 2008). Essa consistência da marca é resultante do grau de proximidade entre a identidade e a imagem da marca (MATTHIESEN; PHAU, 2010).

\subsection{Inovação, redes e marca}

Este trabalho retoma a argumentação do ensaio de Rimoli e Giglio (2009) de que a área de marketing pode ter suas ferramentas gerenciais atualizadas ou potencializadas em função de contribuições das áreas de inovação e de redes. Essas contribuições permitiram enunciar 
Aspectos de inovação e de redes que afetam a imagem da marca: o caso Harley-Davidson e Buell

quatro proposições teóricas sobre o surgimento e a difusão de inovações, produtos e mensagens em uma sociedade em redes.

Quanto à inovação, o ensaio sinaliza que seu surgimento deve ser monitorado cuidadosamente segundo seu tipo e grau de novidade. Isso porque a abordagem tradicional de marketing é adequada às inovações incrementais, mas quanto se tem inovações radicais e de ruptura, é recomendável que ela seja adaptada. Desse modo, propõe-se que os conhecimentos e a gestão de marketing incorporem dois aspectos principais: o surgimento de novos desejos e necessidades que precisam ser satisfeitos, mas que ainda não são conscientes para os consumidores (p. ex. a Internet, quando surgiu); e que tais inovações podem oferecer novas soluções para o atendimento de necessidades antigas, (p. ex.: telefonia celular versus tradicional).

As adaptações dos conhecimentos e da gestão de marketing sugeridas acontecem no âmbito de uma sociedade em rede e por isso devem ser implementadas segundo sua lógica. De um lado, o fortalecimento dos vínculos entre os atores de uma rede via confiança e cooperação tende a aumentar a velocidade de difusão de inovações. De outro, quanto mais coesa for essa rede, maior é a chance de ela erigir barreiras no início do processo de difusão de uma inovação, talvez no sentido de ela ameaçar tal coesão. Porém, se a difusão alcançar uma massa crítica - algo que deixe claro aos atores que a nova mensagem não prejudica a rede - a mesma influência social tenderá a acelerar fortemente o processo de difusão. Desse modo essa sociedade em rede coesa pode ter maior controle sobre a adoção ou não do conteúdo das inovações, mensagens ou produtos difundidos, não havendo como garantir, da parte do difusor, o caráter positivo ou negativo da difusão, entretanto é exatamente isso que traz credibilidade ao processo.

Neste artigo são focalizados os impactos dos aspectos de inovação e de redes sobre a imagem da marca, o que é representado na Figura 3 pelas duas faixas em azul-claro acompanhando o processo de formação da imagem descrito por Kapferer (1992). 


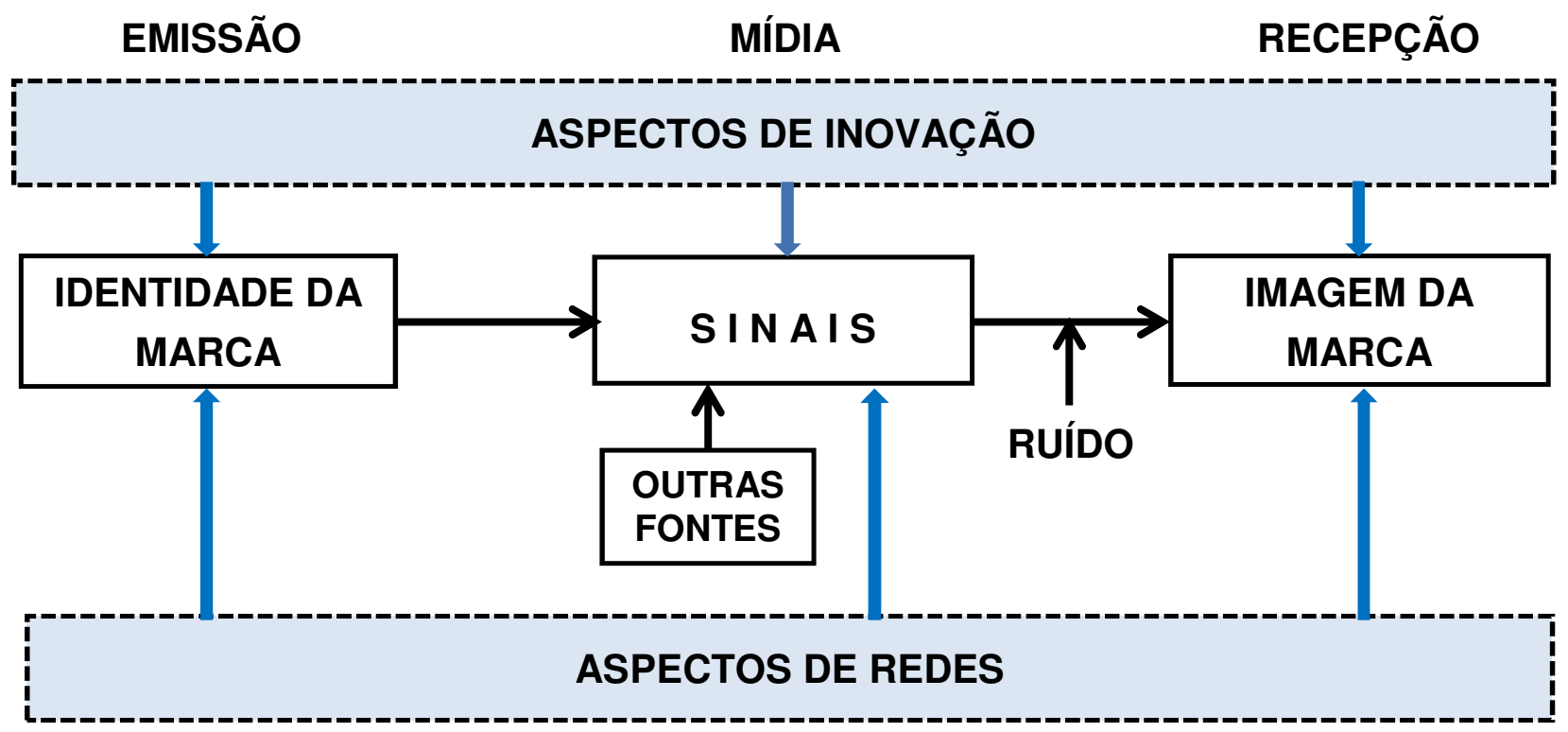

Figura 3 - Inovação, redes e formação da imagem da marca Fonte: Os autores, com base em Kapferer (1992).

Propõe-se que o surgimento de inovações de produto, de processo, organizacional e de marketing, de caráter mais incremental ou radical afeta o processo de formação da imagem da marca e seu monitoramento deve ser efetivo. Os aspectos de inovação envolvidos nessa dinâmica se refletem em necessidades e desejos ainda não conscientes pelos consumidores e em soluções inéditas que contemplam desejos e necessidades antigos. Além disso, considerase que os impactos da inovação acontecem em uma sociedade em rede e é preciso levar em conta os aspectos estruturais (coesão, centralidade, nível de agregação, etc.) e comportamentais (confiança, comprometimento, cooperação, etc.) de seus atores. Entende-se que esses aspectos atuam desde a construção da identidade, passando pela comunicação direcionada aos públicos-alvos e influem no modo como eles recebem e interpretam os sinais emitidos formando a imagem da marca. Para avançar no conhecimento sobre como isso acontece foi realizado um estudo de caso sobre duas marcas globais, cujas características estão descritas na seção seguinte.

\section{CONSIDERAÇÕES METODOLÓGICAS}

Acredita-se que este trabalho seja de natureza descritiva, mas também exploratória, uma vez que visa caracterizar um fenômeno, expresso seu objetivo que é 'analisar como aspectos de inovação e de redes afetam a construção da imagem das marcas globais', aplicado a uma situação empírica na qual há poucos trabalhos com temática semelhante (marcas HD e Buell). 
Aspectos de inovação e de redes que afetam a imagem da marca: o caso Harley-Davidson e Buell

Foi escolhida a estratégia de pesquisa estudo de caso para a realização do trabalho porque, conforme recomenda Yin (2005), a questão de pesquisa é do tipo 'como' e está embutida no objetivo. Além disso, trata-se do estudo de um fenômeno atual em que os limites entre ele e seu contexto não são muito claros. A unidade de análise é a imagem da marca e foi empregada a replicação literal, em busca de resultados congruentes, utilizando-se duas marcas de uma mesma empresa.

Os dados e as informações coletados provêm de três fontes: secundárias, primárias de caráter informal (observação) e primárias de caráter formal (seis entrevistas em profundidade com proprietários das motos e uma com o representante do Grupo Izzo), caracterizando uma triangulação de dados com múltiplas fontes de evidência. Foram identificados três proprietários de moto para cada marca, distribuídos no início, no meio e no final das respectivas faixas etárias descritas nos itens 4.1.3 e 4.1.4. Além disso, todos eles já possuíam uma moto HD ou Buell há pelo menos um ano no momento da entrevista.

E a análise deste trabalho se baseia na estratégia analítica geral 'basear-se em proposições teóricas', servindo-se da técnica analítica específica adequação ao padrão (YIN, 2005). Foram realizadas análises comparativas verticais (resultados sequenciais das questões para cada marca individualmente) e horizontais (entre as duas marcas para cada questão), entre os casos completos e entre a teoria e os dados coletados, procurando identificar unidades, padrões, diferenças, etc. A interpretação dos dados baseou-se também em preceitos e conceitos de análise de conteúdo, que envolvem como passos a pré-análise, a codificação, o tratamento e a interpretação dos resultados. (BARDIN, 1977). Procurou-se também atender aos critérios de validade propostos por Yin (2005) no que tange à triangulação de dados, encadeamento, convergência de evidências, etc.

\section{APRESENTAÇÃO E ANÁLISE DOS DADOS COLETADOS}

\subsection{Informações secundárias: a empresa e as duas marcas}

No ano de 1903, em Milwauke, estado de Wisconsin, EUA, o jovem Bill Harley e dois amigos, Arthur e William Davidson construíram sua primeira motocicleta em um barracão nos fundos da casa de um deles, onde até hoje se encontra o prédio administrativo da empresa de mesmo nome.

O surgimento e a consolidação da empresa HD foi pontuado por vários eventos históricos ao longo do século XX nos EUA e é uma das razões de o atributo patriotismo ser associado à marca naquele país. Assim, em 1916 o presidente Wooddrow Wilson enviou o general John J. 
'Black Jack' Pershing em uma motocicleta HD para capturar Pancho Villa durante a revolução mexicana. E quando os EUA passaram a participar da I Guerra Mundial, foi com um soldado que pilotava uma HD equipada com side-car, que os norte-americanos adentraram o acidentado território alemão pela primeira vez. Após a paz se restabelecer, a HD voltou às pistas em 1921 e se tornou a primeira equipe a vencer uma prova de velocidade a mais de $160 \mathrm{Km} / \mathrm{h}$. Posteriormente, na II Guerra Mundial, após o ataque a Pearl Harbor, a empresa especializou-se em construir motos para uso militar exclusivo, algumas delas equipadas com side-cars sofisticados, com armas automáticas acopladas.

Depois de anos retraído por causa da II Guerra Mundial o mercado americano se reacendeu e muitos dos que haviam lutado se tornaram os principais compradores de motocicletas da marca, pois desejavam vivenciar o espírito da HD como civis. A partir de 1953 a empresa se fortaleceu ainda mais com a falência da Indian, uma concorrente importante, o que a tornou a única fabricante americana de motocicletas. No ano seguinte, com o filme The Wild One (O selvagem, no Brasil), estrelado por Marlon Brando, a imagem dos motociclistas ganhou novos contornos e eles passaram a ser vistos como fora-da-lei, beberrões e arruaceiros. A imagem dos motociclistas passou a ser forte em termos mercadológicos e houve grande procura por motos na época. Pode-se dizer que os anos 1950 foram tomados pelo espírito das motocicletas HD.

No início dos anos 1960, ainda antes da recuperação total do mercado americano, chegaram concorrentes japoneses de grande porte, como a Honda e a Kawazaki, focalizando o segmento de modelos pequenos. No final dessa década, a empresa HD foi adquirida pela American Machine \& Foundry Co (AMF), empresa de produtos para recreação e, devido a seus planos de crescimento rápido, a qualidade das motos HD se deteriorou. Na mesma época, as fabricantes japonesas adentraram o principal segmento da $\mathrm{HD}$, das motos de grande porte. Essa crise alcançou o ponto máximo no início dos anos 1980, quando a empresa quase faliu.

Então os diretores, entre eles o neto do fundador, Willie Davidson, retomaram a propriedade da empresa e elegeram como prioridades a melhoria da qualidade do produto e a atenção especial ao consumidor. No plano interno, a diretoria se voltou para a fábrica de York, Pensilvânia, onde ofereceu aos funcionários opções de compra de ações da empresa e, por estarem produzindo bem, delegou a eles a decisão de fechar as linhas de produção que estivessem provocando defeitos nas motos. E no plano externo, os executivos buscaram estabelecer relacionamento com os consumidores focado em ouvi-los e oferecer-lhes um 
Aspectos de inovação e de redes que afetam a imagem da marca: o caso Harley-Davidson e Buell

produto melhor por meio da comunidade da marca, o Harley Owners Group (HOG), que será descrito adiante.

Com essas medidas os funcionários puderam recuperar o sentimento de que eram artistas que produziam jóias raras, aumentando muito sua identificação com a empresa; e os consumidores se sentiram 'resgatados' pela empresa, respondendo muito positivamente. Os resultados dessas medidas foram a geração contínua e crescente de lucro para a empresa, a alta valorização de suas ações e o grande aumento do prestígio e da reputação da marca. A empresa hoje é profissional e organizada, mas procura manter em sua cultura as qualidades que a consolidaram no mercado. Seus produtos atualmente trazem o design e a concepção técnica de um passado que é tido como glorioso.

Concomitantemente a essa recuperação, outro processo empresarial se desenrolava na empresa HD. Em 1983 o engenheiro e piloto de competição Erik Buell, que havia trabalhado durante quatro anos na tradicional HD resolveu deixar a empresa, para realizar um grande sonho: construir motocicletas totalmente americanas de competição que disputassem o mercado com as importadas, especialmente as japonesas e as italianas. Fundou então, na cidade de East Troy, Wisconsin, a Buell Motorcycle Company. Em 1993 a Buell iniciou uma parceria bem-sucedida com a HD, quando a empresa-mãe comprou $49 \%$ de suas ações e posteriormente, em 1998, o restante do patrimônio foi adquirido por ela. Assim, a história da empresa Buell caracterizou-se como um empreendimento oriundo de outra empresa préexistente (spin-off) e que, decorridos alguns anos, foi incorporado pela empresa mãe. A partir daí a marca Buell passou a se beneficiar de toda tecnologia, conhecimento e credibilidade da marca centenária. Na unidade, são produzidas atualmente cerca de 10 mil motos por ano, além de peças, acessórios e roupas especiais.

\subsubsection{Harley Owners Group - HOG}

Um dos aspectos únicos da empresa HD é o envolvimento de seu pessoal e das concessionárias com os clientes e suas experiências, conforme atesta a existência pujante do Harley Owners Group - HOG. Mais de 250.000 proprietários de HD pertencem a um de seus mais de 800 Capítulos (chapters, sub-grupos do HOG global). Seus membros recebem uma newsletter bimestral e participam com a família de passeios de motocicleta, bem como de reuniões e cafés da manhã, em base mensal ou semanal, tudo isso patrocinado pela empresa e pelas concessionárias. Há também um subgrupo chamado Ladies of Harley - LOH, composto por mulheres, que corresponde a $10 \%$ dos proprietários de HD. 
Nos EUA tradicionalmente os passeios organizados pelo HOG contemplam a praia de Daytona e a cidade de Milwaukee, onde a empresa nasceu. No Brasil, os passeios são organizados pelos diferentes Capítulos e acontecem entre os pontos turísticos das cidades dos respectivos estados como Rio de Janeiro (Búzios), Santa Catarina (Florianópolis), Minas Gerais (Tiradentes), etc.

Os funcionários da HD - desde os altos executivos, passando pelo chefe de engenharia e cargos mais baixos - tem participado de encontros importantes do HOG. Desse modo, eles passam a conhecer seus clientes pessoalmente e ficam sabendo como as motos são utilizadas por eles e recolhem as sugestões de seus membros, fortalecendo os laços entre os proprietários das motocicletas e entre eles e os funcionários da empresa.

\subsubsection{A configuração de negócios da HD no Brasil}

A configuração de negócios da Harley-Davidson Motor Company no país, esquematizada na Figura 4, mostra inicialmente a matriz, que fabrica os produtos das marcas HD e Buell, sendo que a partir da linha pontilhada é mostrado o processo de comercialização no Brasil. O Grupo Izzo é a empresa que controla esse processo, em função do contrato de importação e distribuição exclusivo que possui com a matriz. As concessionárias e as lojas HD e Buell constituem na realidade braços do grupo Izzo e não empresas independentes. Trata-se de uma configuração de negócios bastante simples, com características mais próximas de uma cadeia produtiva tradicional do que propriamente de uma rede de negócios. A relação entre os atores é representada por linhas com setas nas pontas, indicando fluxo bidirecional de pelo menos um entre três elementos: bens, serviços e informações. As linhas que conectam os clientes HD e seu subgrupo HOG são mais grossas em relação às que ligam os clientes Buell aos demais atores porque esses últimos privilegiam menos os relacionamentos que os dois primeiros.

As linhas na cor laranja indicam os elementos da configuração de negócios - Grupo Izzo, clientes HD, HOG e clientes Buell - que mantém contato direto com a matriz. O Grupo Izzo é quem importa e cuida do marketing das motocicletas no Brasil (distribuição, comunicação, venda e pós-venda). No caso dos clientes HD existe troca de informações e marketing direto destinados a manter sua identidade e valores históricos, sendo que essas ações são diferenciadas quando se trata do HOG. O mesmo se dá em relação aos clientes Buell que, no entanto se restringe a troca de informações mais técnicas. 
Aspectos de inovação e de redes que afetam a imagem da marca: o caso Harley-Davidson e Buell

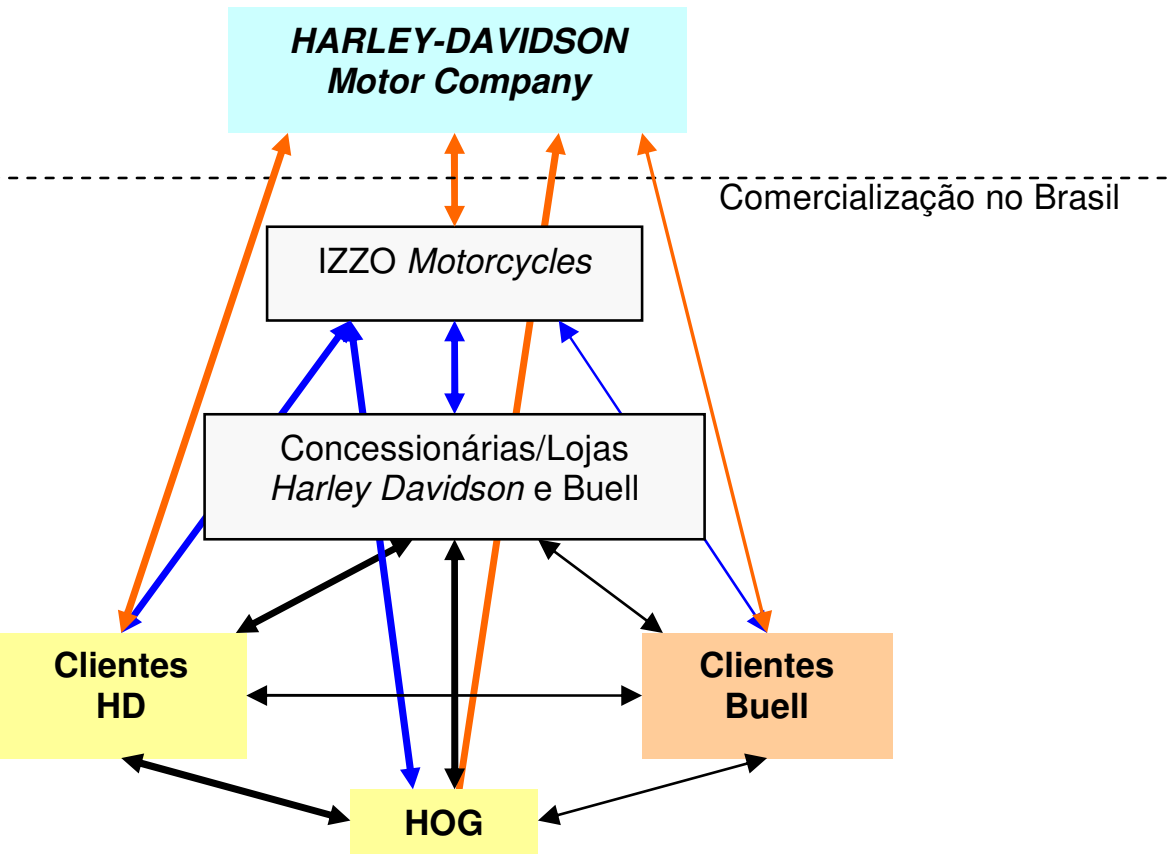

Figura 4 - Esquema da configuração de negócios das marcas HD e Buell.

Fonte: os autores

Já as linhas em azul mostram os contatos do Grupo Izzo com clientes HD, HOG e clientes Buell e tem características similares aos da matriz com esses atores, mas adaptado ao contexto brasileiro. E as linhas na cor preta ilustram o relacionamento entre as concessionárias e lojas de serviços HD (braços do Grupo Izzo) com os clientes HD, o HOG e com os clientes Buell, bem como o relacionamento entre os clientes em si.

\subsubsection{A marca HD}

Os documentos verificados mostram que a marca HD expressa uma experiência, uma atitude, um estilo de vida e um veículo para dizer quem é seu proprietário, traduzindo valores como individualidade e liberdade pessoal. Essa liberdade se refere a estar livre tanto de confinamento físico e de estruturas e valores sociais dominantes. Outro valor importante é a masculinidade, inspirada parcialmente no já mencionado filme The wild one, de 1954, no qual o ator Marlon Brando pilota uma moto com esse estilo. A HD é a maior, a mais pesada, a mais ruidosa e assim, a mais vigorosa motocicleta das estradas. Há diversas jaquetas de couro, botas pesadas, cromos e reforçam esses valores em assim, a personalidade da marca se confunde com a própria história da empresa.

A marca HD revela características como um caráter clássico, ligado ao tradicionalismo e ao nacionalismo, além de autenticidade, sobriedade e elitismo em seu relacionamento com o 
mercado. A HD é identificada como um elemento de valor fixo, atemporal, como uma jóia rara de grande valor, que estão inculcados tanto nos administradores e funcionários da empresa quanto nos consumidores da marca.

As HD são motocicletas clássicas, que trazem consigo toda a nostalgia e espírito de épocas e acontecimentos do passado na contextualização de seu usuário, mais conservador. Apresentam design bom e funcional e, apesar de suas atualizações tecnológicas não serem tão desenvolvidas quanto aquelas dos concorrentes, não chegam a comprometer os propósitos do produto. Ao contrário, servem como fator de identidade e diferenciação, por serem consistentes com aspectos como tradicionalismo e estabilidade da marca.

Entretanto, cabe ressaltar a importância da inovação de produto no contexto da marca em outra época. Por exemplo, os motores em "V", que hoje constituem a base do tradicional modelo custom de HD, foram considerados inovadores ao serem lançados pela empresa. As HD custom podem ser personalizadas ao gosto de cada proprietário, a partir dos acessórios que podem ser instalados. Assim, no contexto atual, inovação não é importante para a marca HD, mas em diferentes momentos de sua história ela foi a responsável por diversos atributos que hoje valorizam a marca tornando-a clássica. Tais inovações eram relacionadas ao design (tanque em forma de gota, assento em forma de sela, farol redondo, uso de cromados, grande distância entre eixos, posição de pilotagem com boa ergonomia, que trouxe conforto para viagens longas) e técnicas, como o motor em "V" já mencionado.

O envolvimento dos 'harleiros', como são chamados os proprietários no Brasil, com a marca HD é assim, muito mais próximo, intimista e engajado do que por exemplo, aquele que ocorre entre os proprietários de motocicletas japonesas e as respectivas marcas. Essas pessoas focalizam benefícios funcionais e se preocupam com aspectos tecnológicos e de desempenho, como equipamentos digitais, marchas reversas, velocidades mais altas e motores mais silenciosos. Diferentemente, os proprietários de motocicletas HD estão mais ligados a benefícios emocionais e auto-expressivos.

Os proprietários de HD constituem um público basicamente masculino (cerca de 90\%); entretanto as mulheres também demonstram afinidade e interesse por essas motocicletas, como mostra o LOH, já mencionado. Estão inseridos na faixa etária chamada de "maturidade", oscilando entre 36-59 anos. Este grupo é formado por pessoas bem-sucedidas profissionalmente pertencentes às classes alta e média-alta e demonstram satisfação e fidelidade ao produto e à marca. A grande maioria pretende adquirir outra moto HD quando for trocar a atual. Desse modo, possuir um relacionamento com uma organização e com um 
Aspectos de inovação e de redes que afetam a imagem da marca: o caso Harley-Davidson e Buell

produto com personalidade forte é algo satisfatório e recompensador, assim como o é a ligação com o HOG, um grupo que compartilha valores pessoais e um estilo de vida.

Como pontos negativos da marca observam-se algumas deficiências apontadas sobre o Grupo Izzo relativas à sua participação como intermediário entre o fabricante e os consumidores, bem como em relação ao serviço de pós-vendas. A Figura 5, a seguir, ilustra a motocicleta e a respectiva marca HD.
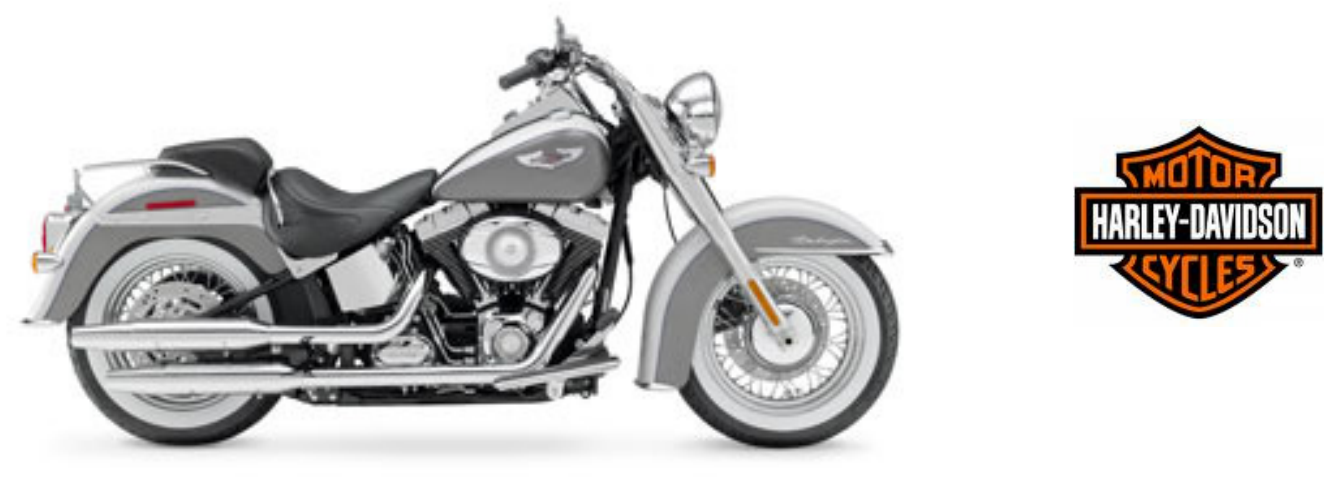

Figura 5 - Harley-Davidson modelo De Luxe. Fonte: Site Harley-Davidson Brasil.

\subsubsection{A marca Buell}

Apesar de pertencer à mesma empresa, a marca Buell não dispõe de experiência similar à conquistada pela HD durante os anos de sua existência e carrega apenas a força da marca do fabricante, o que faz com que seus usuários dêem maior valor às características do produto.

A investigação realizada revelou que essa marca apresenta uma personalidade de caráter inovador, extravagante e jovial e se caracteriza pelo conhecimento tecnológico, percebido desde seu surgimento. Nas motocicletas Buell sobressaem os atributos qualidade, tecnologia e desempenho. Essas motos se diferenciam das HD, bem como das concorrentes, principalmente pelo atributo inovação, em que design, soluções mecânicas e atualizações tecnológicas se destacam. Especificamente a vocação para inovar de todos os modelos Buell foi construída em torno da chamada 'trilogia de tecnologia'. Ela consiste em três regras para a fabricação de motos: baixo peso, rigidez de quadro e centralização de massas, atributos que são valorizados em motocicletas ágeis. Exemplos de inovações envolvendo centralização de massas são: posicionar o escapamento sob a motocicleta, em vez de na lateral ou na traseira; posicionar o tanque de combustível no interior do quadro de alumínio, com capacidade para armazenar 16,7 litros de gasolina. Pelo mesmo motivo, o óleo do motor também é mantido dentro da balança traseira. No lugar tradicional do tanque, estão o filtro de ar e o corpo da 
injeção, que podem ser vistos através da capa acrílica translúcida, inspirada nos computadores iMac da Apple. Como resultado, o chassi rígido reduz a flexibilidade, mas aumenta a estabilidade da motocicleta, especialmente em pisos irregulares. Outro ponto é a limitação ao mínimo possível do peso de todos os componentes não sustentados por molas. Isso permite que os pneus mantenham contato constante com a pista. A menor massa não suspensa também resulta em maior agilidade e assegura melhores condições de tração, o que traz desempenho, estabilidade e segurança. Outra solução tecnológica inovadora é o freio Zero Torsion Load (ZTL), sistema no qual o disco de freio é fixado no aro da roda dianteira pela parte externa e não no cubo central, como nas demais motos. Esse processo impede que a frenagem torça o disco e a torna mais segura, além de reduzir em três quilos o peso na parte frontal da motocicleta.

Os proprietários de Buell são em sua quase totalidade homens das classes alta e média alta, com idades variando entre 25 e 35 anos. São pessoas bem-sucedidas profissionalmente, mas que, em sua maioria, demonstraram baixa intenção de adquirir outra Buell no momento da troca de sua motocicleta atual. Quanto ao relacionamento com o consumidor, a motocicleta Buell apresenta um clima dinâmico, retratado pela vitalidade revelada na apresentação constante de novidades e pelo senso de oportunidade demonstrado. É também superficial, tendo em vista a rapidez com que evoluem os produtos e em decorrência do apelo ao público mais jovem, selecionado até pelas condições de uso impostas por estas motocicletas. Na Buell foi identificada a imagem de prestígio pelos consumidores, por ter um produto muito inovador - diferente da grande maioria das motocicletas - e impactante principalmente em design.

Existe uma forte concorrência das motos japonesas em relação a essa marca, que são tecnologicamente bastante desenvolvidas. Talvez por essa razão tenha surgido o interesse do fabricante HD em adquirir a Buell, cujas motocicletas incorporam inovações em tecnologia, desempenho e design, mas também utilizam os mesmos motores em "V" adotados pelas clássicas HD. Com essa ação, a empresa passou a competir no segmento de mercado em que as motos japonesas atuam. A Figura 6, a seguir ilustra a motocicleta e a marca Buell. 
Aspectos de inovação e de redes que afetam a imagem da marca: o caso Harley-Davidson e Buell
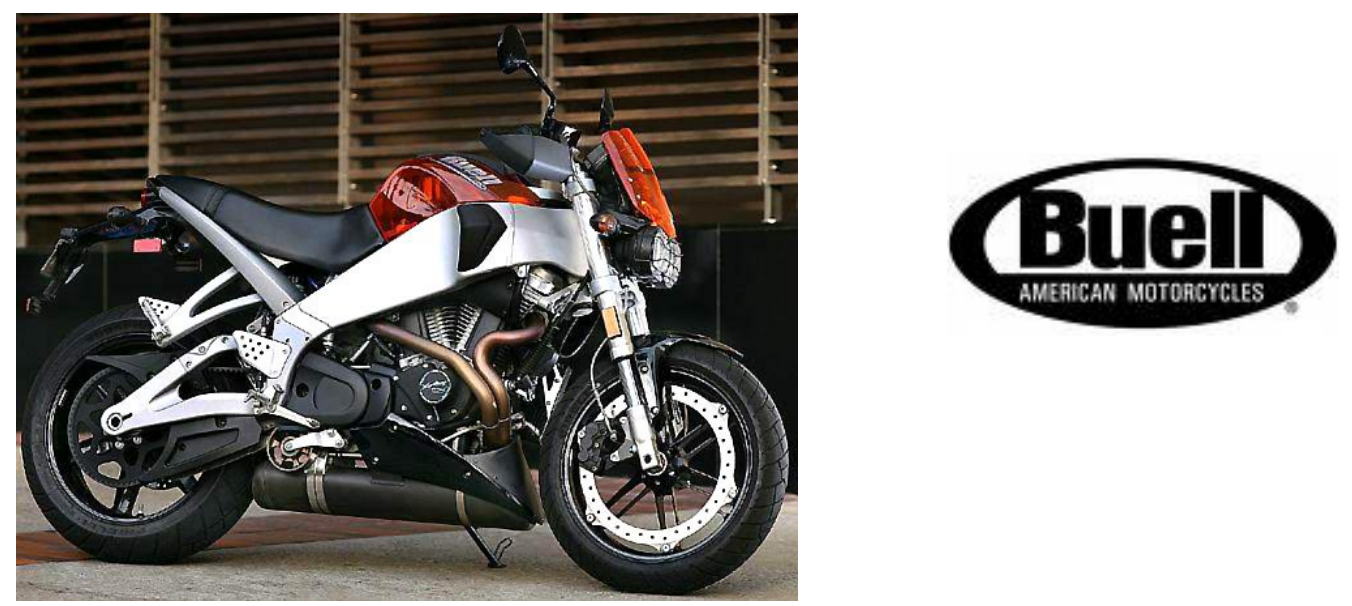

Figura 6 - Buell modelo City Cross. Fonte: Site Buell Brasil.

\subsection{Informações primárias: entrevistas e observação}

A seguir são apresentados quadros relativos a informações primárias coletadas principalmente via entrevistas em profundidade e apoiadas pela convivência de um dos autores do artigo com a marca. De um modo geral observou-se grande aderência desses resultados ao que foi levantado preliminarmente na coleta de informações secundárias. Esse resultado geral é respaldado pelo cuidado metodológico de identificar respondentes das entrevistas que estivessem no início, no meio e no final das faixas etárias características de cada marca mencionados no item 3. Outro ponto é que todos os respondentes são possuidores das respectivas motos a mais de um ano.

A configuração de negócios da HD esquematizada no Quadro 2 identifica seus três elementos ou atores principais: o Grupo IZZO, que inicia o processo, que se dá pela importação dos produtos dos EUA até sua entrega e utilização pelos clientes das duas marcas.

O exame das características da configuração de negócios das marcas HD e Buell no Brasil, oriundas das entrevistas em profundidade realizadas e sistematizadas no Quadro 2, revelou congruência com o esquema apresentado na Figura 4, que ilustra a descrição com base nas informações secundárias. Além disso, ela se aproxima mais de uma estrutura de distribuição tradicional de produtos do que de uma rede de negócios. Ainda assim, talvez se possam caracterizar algumas redes de consumidores, como no caso dos grupos de proprietários de motocicletas HD e do HOG, nos quais atributos como confiança, cooperação e interdependência apareceram com maior ênfase. 
Quadro 2 - Características da configuração de negócios HD e Buell

\begin{tabular}{|c|c|c|}
\hline Clientes HD & Clientes Buell & Grupo Izzo \\
\hline $\begin{array}{l}\text { - Predominantemente masculinos } \\
\text { (90\%) e concentrados na faixa } \\
\text { entre 36-59 anos. } \\
\text { - Há relação próxima entre os } \\
\text { proprietários de motos HD, para } \\
\text { troca de informações sobre } \\
\text { produtos e eventos. } \\
\text { - Há um grau de consistência e } \\
\text { confiança relativamente bem- } \\
\text { desenvolvido no grupo. } \\
\text { - São bastante interconectados em } \\
\text { função da existência longeva da } \\
\text { marca. } \\
\text { - Consequentemente a confiança e } \\
\text { o comprometimento entre eles são } \\
\text { bem-desenvolvidos. } \\
\text { - Apresentam certo nível de } \\
\text { descontentamento com os serviços } \\
\text { prestados e assistência técnica. }\end{array}$ & $\begin{array}{l}\text { - Masculinos em sua quase } \\
\text { totalidade (mais de } 99 \% \text { ) e entre } 25 \\
\text { e } 35 \text { anos. } \\
\text { - Esportivos e individualistas, } \\
\text { (pilotam sozinhos com freqüência). } \\
\text { - Marca é relativamente nova (mais } \\
\text { de } 25 \text { anos). } \\
\text { - Acreditam que há que há } \\
\text { confiança e entre eles, pois trocam } \\
\text { de informações quando há } \\
\text { problemas com as motos } \\
\text { - Participam relativamente pouco } \\
\text { de eventos promovidos pela HD. } \\
\text { - As conexões entre usuários } \\
\text { acontecem em menor escala. } \\
\text { - Inexistência, no âmbito dessa } \\
\text { marca, de um grupo coeso como o } \\
\text { HOG. } \\
\text { - Apresentam certo nível de } \\
\text { descontentamento com os serviços } \\
\text { prestados e assistência técnica. }\end{array}$ & $\begin{array}{l}\text { - Possui contrato exclusivo de } \\
\text { importação em comercialização das } \\
\text { marcas no Brasil. } \\
\text { - É o único canal por onde } \\
\text { obrigatoriamente passa o todo } \\
\text { processo de comercialização } \\
\text { - Exerce controle sobre ele e suas } \\
\text { decorrências. } \\
\text { - Em resumo, centraliza as ações e } \\
\text { exerce a governança de todo o } \\
\text { processo. } \\
\text { - Apesar de reclamações sobre } \\
\text { serviços, o Grupo Izzo considera } \\
\text { que há confiança e } \\
\text { comprometimento nas atividades } \\
\text { que controla e os clientes. }\end{array}$ \\
\hline
\end{tabular}

Fonte: os autores

Os Quadros 3 e 4 se referem à caracterização da imagem das duas marcas e, embora eles não mostrem informações sobre as respectivas identidades, cabe informar que elas foram coletadas e verificou-se grande aderência entre ambas para as duas marcas. Ou seja, em função da grande proximidade entre a identidade que a empresa objetivou emitir para seus públicos e a imagem que estes apreenderam desse esforço, optou-se por mostrar nos referidos quadros apenas a imagem da marca, uma vez que as informações sobre as identidades são muito semelhantes. Isso é um indicador da força e da solidez dessas marcas.

Em primeiro lugar ressaltam-se as semelhanças entre as duas marcas como o fato de ambas valorizarem a sensação de liberdade que proporcionam aos proprietários das motos, assim como o quanto cada tipo de consumidor é adepto de sua marca. Entretanto, essa sensação de liberdade se funda em bases diferentes para cada uma: a marca HD cultua a liberdade de confinamento e de convenções sociais, mas é adepta de atividades em grupo, 
Aspectos de inovação e de redes que afetam a imagem da marca: o caso Harley-Davidson e Buell

como exemplificam as atividades do HOG com a família e os cafés da manhã nas concessionárias. Em contraposição, a liberdade para a Buell se baseia na esportividade e na liberdade individual de sair e explorar lugares sem esposas ou namoradas.

Outras distinções envolvem a solidez e o sentido de permanência da marca HD, com seu design clássico e concepções técnicas que tem por base o que foi desenvolvido nos anos 1950. A imagem dessa marca se mistura, até certo ponto com a da organização, pois muitos conceitos são compartilhados por ambas. A personalidade é robusta e genuína e além disso, as motos HD foram idealizadas para rodar principalmente em estradas e os usuários são predominantemente homens entre 36 e 59 anos.

Quadro 3 - Imagem da marca HD

\begin{tabular}{|c|c|c|c|}
\hline $\begin{array}{c}\text { A marca como } \\
\text { produto }\end{array}$ & $\begin{array}{c}\text { A marca como } \\
\text { organização }\end{array}$ & $\begin{array}{c}\text { A marca como } \\
\text { pessoa }\end{array}$ & $\begin{array}{c}\text { A marca como } \\
\text { símbolo }\end{array}$ \\
\hline $\begin{array}{l}\text { - É um produto único e } \\
\text { exclusivo. } \\
\text { - Traz em si toda uma } \\
\text { história e tradição. } \\
\text { - Constitui o objeto de } \\
\text { desejo para qualquer } \\
\text { amante de motos do } \\
\text { estilo custom, um mito. } \\
\text { - Tem design clássico, } \\
\text { conservado até os dias de } \\
\text { hoje, } \\
\text { - São rústicas mas } \\
\text { apresentam alta qualidade } \\
\text { nas peças que compõem. } \\
\text { - São concebidas para o } \\
\text { uso em estradas, } \\
\text { principalmente em } \\
\text { decorrência de seu porte. }\end{array}$ & $\begin{array}{l}\text { - A organização confere } \\
\text { credibilidade e } \\
\text { confiabilidade ao } \\
\text { produto. } \\
\text { - Não se encontra uma } \\
\text { moto da marca HD } \\
\text { abandonada sem uso, } \\
\text { como acontece com a } \\
\text { maioria de suas } \\
\text { concorrentes. } \\
\text { - Os produtos da marca } \\
\text { HD, mesmo após décadas } \\
\text { de uso, continuam a } \\
\text { oferecer um grande } \\
\text { desejo pela maioria dos } \\
\text { motociclistas. }\end{array}$ & $\begin{array}{l}\text { - Tem personalidade } \\
\text { robusta, confiável, e } \\
\text { genuína, sendo única. } \\
\text { - Ao mesmo tempo é } \\
\text { "personalizável" ao gosto } \\
\text { do proprietário. } \\
\text { - É voltada ao estilo } \\
\text { clássico e estradeiro. } \\
\text { O relacionamento do } \\
\text { cliente com a marca é } \\
\text { intenso, fortalecido pelas } \\
\text { atividades oferecidas pelo } \\
\text { HOG. }\end{array}$ & $\begin{array}{l}\text { - Representa um sonho } \\
\text { do passado que se } \\
\text { materializa nas motos e } \\
\text { nos respectivos } \\
\text { acessórios. } \\
\text { - Esse sonho se sustenta } \\
\text { em atributos como } \\
\text { originalidade e } \\
\text { legitimidade } \\
\text { - Usuários buscam } \\
\text { glamour e não precisam } \\
\text { provar nada a si mesmos. } \\
\text { - Liberdade, tanto física } \\
\text { quanto de convenções } \\
\text { sociais. } \\
\text { - É a marca mais tatuada } \\
\text { nos EUA e em grande } \\
\text { escala no Brasil também. }\end{array}$ \\
\hline
\end{tabular}

Fonte: os autores. 
Quadro 4 - Imagem da marca Buell

\begin{tabular}{|c|c|c|c|}
\hline A marca como produto & $\begin{array}{c}\text { A marca como } \\
\text { organização }\end{array}$ & A marca como pessoa & A marca como símbolo \\
\hline $\begin{array}{l}\text { - Motos arrojadas, } \\
\text { esportivas e singulares, } \\
\text { diferentes de qualquer } \\
\text { outra fabricada em série. } \\
\text { - Design inovador e } \\
\text { moderno } \\
\text { - Pilotagem adequada } \\
\text { tanto na cidade quanto na } \\
\text { estrada, desde que possua } \\
\text { bom asfalto. } \\
\text { - Usuários entre } 25 \text { e } 35 \\
\text { anos. }\end{array}$ & $\begin{array}{l}\text { - História e tradição da } \\
\text { fabricante reforçam } \\
\text { atributos próprios da } \\
\text { marca, como inovação, e } \\
\text { boa dirigibilidade. } \\
\text { - Características } \\
\text { inovadoras com a } \\
\text { credibilidade da marca do } \\
\text { fabricante HD; utiliza seu } \\
\text { motor. }\end{array}$ & $\begin{array}{l}\text { - Orgulho em possuir } \\
\text { uma moto dessa marca. } \\
\text { - Personalidade revela } \\
\text { autenticidade e inovação. } \\
\text { - Diferencia-se da } \\
\text { maioria dos concorrentes, } \\
\text { moto futurista. } \\
\text { - Relacionamento com a } \\
\text { marca é menos intenso do } \\
\text { que o da HD. } \\
\text { - Poucos são os } \\
\text { proprietários de Buell que } \\
\text { participam das atividades } \\
\text { oferecidas pelo HOG. }\end{array}$ & $\begin{array}{l}\text { - Simboliza atributos } \\
\text { como arrojo, jovialidade } \\
\text { e inovação. } \\
\text { - É a motocicleta do } \\
\text { futuro, acessível apenas a } \\
\text { poucos felizardos. } \\
\text { - Carrega a herança, de } \\
\text { credibilidade e da } \\
\text { rusticidade oferecida pelo } \\
\text { motor em "V", da sua } \\
\text { irmã mais velha e } \\
\text { conservadora, a HD. }\end{array}$ \\
\hline
\end{tabular}

Fonte: os autores.

Já em relação à Buell, seus adeptos são homens virtualmente na totalidade e integram uma faixa etária concentrada entre 25 e 35 anos. Esse grupo é bem menos numeroso e bem mais recente - enquanto a marca HD é centenária, a marca Buell foi iniciada em 1983 - mas, como acontece com a 'marca-irmã', é bastante aderente aos atributos da marca Buell. Entre eles estão a inovação e a atualização tecnológica das motos, que é mais adequada à pilotagem em espaços urbanos. Esses veículos apresentam design inovador, centralização de massa e elementos que melhoram a dirigibilidade, especialmente nas curvas. Atributos como confiança e cooperação existem, mas restritos à troca de informações sobre os produtos e seus problemas, sendo mais tênues do que na marca HD. Algo que ajuda a consolidar esta marca e é valorizado pelos proprietários das motos Buell é a reputação do fabricante, que a marca carrega.

Na sequência são apresentados aspectos de inovação e de redes afetam as duas marcas, bem como são exploradas as proposições apresentadas na introdução. Os entrevistados disseram que inovação não é importante para a HD, pois ela traduz um conceito estabelecido pelo produto há muito tempo, com valores consolidados e tradicionais que a diferenciam da concorrência. O oposto ocorre com a marca Buell.

Quanto às proposições formuladas com base nas informações secundárias, todos os entrevistados as confirmaram. A primeira delas afirma que aspectos de inovação afetam com maior intensidade a marca Buell. Foram citados design e inovações tecnológicas como baixo centro de gravidade, sistema de freios, etc. sendo que, de tradicional a marca traz apenas o REAd I Porto Alegre - Edição 75 - Nº 2 - maio/agosto 2013 - p. 401-432 
Aspectos de inovação e de redes que afetam a imagem da marca: o caso Harley-Davidson e Buell

motor HD. Os usuários da Buell apreciam inovações e a idéia geral é que essa marca é distinta da marca HD: conforme um dos entrevistados ela 'veio para inovar'. São motos esportivas e inovação faz muito sentido para seus usuários. Observa-se, conforme essas declarações, que o posicionamento das duas marcas está adequado, pois cria valores distintos para públicos diferentes, ainda que sequenciais.

A segunda proposição diz que os aspectos de redes afetam mais a marca HD e apresentou também alto nível de concordância dos entrevistados, porque seus usuários apreciam a troca de informações, a cooperação, os passeios em grupo com a família (HOG), os cafés da manhã nas concessionárias, etc. Os respondentes da Buell reconheceram esses atributos à marca HD, mas ressaltaram que existe confiança também entre os usuários da marca Buell.

E terceira proposição, afirma que a inovação teve grande importância em um dado contexto histórico da marca HD, o que favorece sua força atualmente. A concordância também foi expressiva, mas mais intensa entre os usuários da marca HD, que conhecem melhor sua história do que os da marca Buell. Ressalta-se a resposta do representante do Grupo Izzo, ilustrativa da veracidade da proposição "conhecendo a evolução histórica da motocicleta $\mathrm{HD}$, percebemos que inovações como o tanque em forma de gota, a grande distância entre eixos, o motor em ' $\mathrm{V}$ ', o uso de cromados, etc. foram criadores do estilo HD chamado custom, que é copiado pela concorrência".

\section{CONSIDERAÇÕES FINAIS}

Este trabalho é uma das primeiras aplicações do ensaio teórico de Rimoli e Giglio (2009) e tem como pressupostos as seguintes tendências: a) o aumento numérico e de complexidade das inovações na sociedade; b) a emergência de uma sociedade que se organiza em redes de relações; e c) a mudança de mercados de produtos para mercados de marcas. Nesse panorama buscou-se saber como aspectos de inovação e de redes afetam a imagem das marcas globais. Para a realização do estudo, foram escolhidas as marcas das motocicletas HD e Buell. A revisão da literatura se baseou no artigo conceitual citado que traz contribuições e proposições teóricas das áreas de inovação e de redes para marketing e foi direcionada ao tema marcas.

Os resultados revelaram grande aderência entre a coleta de dados secundários e primários, que permitiram tanto a resposta congruente ao objetivo formulado quanto o exame das três proposições aplicadas ao objeto de estudo (marcas HD e Buell). Conforme mencionado, foram tomados cuidados metodológicos para respaldar os resultados encontrados. 
Primeiramente descreveu-se a configuração de negócios das marcas no Brasil, caracterizada como uma estrutura tradicional de comercialização e não como uma rede de negócios, composta de três atores principais: o Grupo Izzo (responsável pelo processo de comercialização), os clientes HD e seu subgrupo HOG e os clientes Buell. Em seguida, foram descritas as imagens das duas marcas, sendo que em essência, a HD se caracteriza por perenizar um sonho e um estilo de vida em escala mundial; já a Buell se define pela liberdade individual oriunda da inovação e da esportividade. Verificou-se também que aspectos relacionados a inovação, (design arrojado e atributos técnicos de melhoria de desempenho e dirigibilidade) afetam a marca Buell; e que aspectos de redes, como confiança e cooperação, são importantes para a marca HD e para o HOG.

Quanto às proposições aplicadas, todas foram confirmadas, pois os resultados dos três tipos de investigação mostraram convergência tanto no sentido de evidências confirmatórias quanto complementares. Desse modo, as evidências encontradas indicam que aspectos de inovação, como design e atualizações tecnológicas afetam mais intensamente a marca Buell (proposição 1) ao passo que aspectos de redes, como confiança, cooperação e relacionamento afetam com maior intensidade a marca HD (proposição 2). E também foi evidenciado que embora os aspectos de inovação não sejam importantes para a HD hoje em dia, eles foram fundamentais para a consolidação da marca nos anos 1950, quando foi criado o estilo custom da HD (proposição 3). Esse estilo é considerado até hoje uma das referências da marca e é imitado pelas concorrentes.

Algo que não estava explícito no objetivo nem nas proposições ou nos questionamentos das entrevistas, mas que apareceu durante a coleta e análise dos dados é o fato de a empresa Harley-Davidson talvez utilizar a estratégia de direcionar os proprietários de Buell a se tornarem proprietários de HD em longo prazo. Em apoio a essa asserção, há algumas evidências. Em primeiro lugar, o fato de as faixas etárias serem seqüenciais e (os proprietários de Buell concentram-se entre 25 e 35 anos; e os de HD entre 36 e 59 anos). Em segundo, embora o perfil dos consumidores das duas marcas seja distinto, pode ser considerado complementar, relativamente ao ciclo de vida de uma pessoa. Especificamente, os mais jovens tenderiam a buscar mais inovação e emoção e seriam mais individualistas (atributos da Buell) mas, com o correr dos anos, passariam a valorizar estabilidade, tradição e atividades em grupo (atributos da HD). E em terceiro lugar, os possuidores de Buell em geral tendem a não comprar uma nova moto da mesma marca, mas os de HD sim. Essas reflexões poderiam ser objeto de outro estudo, em continuação a este. 
Aspectos de inovação e de redes que afetam a imagem da marca: o caso Harley-Davidson e Buell

Quanto às implicações dos resultados desta pesquisa para entender a formação da imagem da marca e assim contribuir para sua gestão, pode-se dizer que a investigação permitiu alguns avanços. A confirmação das proposições aplicadas evidenciam alguns pontos: trata-se de marcas de motocicletas complementares no sentido de se destinarem a públicos-alvos diferentes, porém sequenciais ao menos em características como faixa etária e nível socioeconômico e comportamento. Fatos como a inovação ser prevalente na marca Buell, as redes na HD e ainda a inovação ser sido fundamental para consolidar a força desta última, que se sustenta até hoje por características de redes, indica a importância desses aspectos em sua evolução e sucesso. No caso específico deste artigo, essas relações dificilmente teriam sido descobertas se esses aspectos não tivessem sido objetivamente investigados. Acredita-se que isso respalda a consideração explícita dos aspectos de inovação e de redes na formação e gestão da imagem das marcas em geral. Enfim, por constituírem forças e características prevalentes na sociedade atual, é recomendável que inovação e redes sejam incorporados ao estudo da formação da imagem e da gestão das marcas em geral, conforme ilustra a Figura 3.

Deve-se ressalvar que esses resultados são oriundos de uma investigação descritivoexploratória de caráter qualitativo. Porém, a grande consistência, convergência e encadeamento das evidências, além de outros cuidados metodológicos trazem segurança quanto aos resultados obtidos e atendem aos critérios de validade apresentados por Yin (2005). De todo modo são desejáveis mais estudos relativos a esse tema, que tragam aprofundamento de caráter qualitativo e quantitativo, bem como a replicação deste estudo aplicado a outras marcas.

\section{REFERÊNCIAS}

AAKER, D. Building strong brands. New York: The Free Press, 1996.

APOSTOlOPOUlOU, A.; BIGGERS, M. Positioning the New Orleans Hornets in the "Who Dat?" City. Sport Marketing Quarterly, n. 19, p. 229-234, 2010.

BARDIN, L. Análise de conteúdo. Lisboa: Edições 70, 1977.

BARICH, H.; KOTLER, P. A framework for marketing image management. Sloan Management Review, v. 32, p. 94-104, 1991. 
Celso Augusto Rimoli, Léo Eduardo Pastori Noronha \& Francisco Antonio Serralvo

BENGTSSON, A.; BARDHI, F.; VENKATRAMAN, M. How global brands travel with consumers. An examination of the relationship between brand consistency and meaning across national boundaries. International Marketing Review, v. 27, n. 5, p. 519-540, 2010.

BERNSTEIN, D. Rhetoric and reputation: some thoughts on corporate dissonance.

Management Decision, v. 47, n. 4, p. 603-615, 2009.

CASTELLS, M. Materials for an exploratory theory of the network society. British Journal of Sociology, v. 51, n. 1, jan/fev, p. 5-24, 2000.

CHRISTENSEN, C. The innovator's dilemma. 2. ed. New York: Harperbusiness, 2000.

DANES, J. E.; HESS, J. S.; STORY, J. W.; YORK, J. L. Brand image associations for large virtual groups. Qualitative Market Research: An International Journal, v. 13, n. 3, p. 309$313,2010$.

DWYER, F. R.; SCHURR, P. H.; OH, S. Developing buyer-seller relationships. Journal of Marketing; v. 51; p. 11-27, abr. 1987.

EBERS, M.; JARILLO, J. The construction, forms and consequences of industry networks. International Studies of Management and Organizations, v. 27, n. 4. p. 3-21, 1997.

GULATI, R.; GARGIULO, M. Where do interorganizational networks come from? American Journal of Sociology. v. 104, n. 5, p.1439-1493, mar. 1999.

GUTHRIE, M.; KIM, H. The relationship between consumer involvement and brand perceptions of female cosmetic consumers. Brand Management, v. 17, n. 2, p. 114-133, 2009.

HAKANSSON, H.; SNEHOTA, I. Developing relationships in business networks. London: T. J. Press, 1995.

HILLS, S. B.; SARIN, S. From market driven to market driving: an alternate paradigm for marketing. Journal of Marketing Theory and Practice. v. 11, n. 3, p. 13-23, 2003. 
Aspectos de inovação e de redes que afetam a imagem da marca: o caso Harley-Davidson e Buell

JOHN, G.; WEISS, A.; DUTTA, S. Marketing in technology intensive markets: toward a conceptual framework. Journal of Marketing, Special Issue, v. 63, p.78-91, 1999.

KAPFERER, J. N. New strategic brand management. 3. ed. London: Kogan Pages, 2004.

KAPFERER, J. N. As Marcas, capital da empresa: criar e desenvolver marcas fortes. 3. ed. Porto Alegre: Bookman, 2003.

KAPFERER, J. N. Strategic brand management. New York: Free Press, 1992.

KAPFERER, J. N. As Marcas, capital da empresa. Lisboa: Edições CETOP, 1991.

KELLER, K. L. Strategic Brand Management. 3. ed. Upper Saddle River: Pearson, 2008.

KEMPE, D.; KLEINBERG, J.; TARDOS, E. Influential nodes in a diffusion model for social networks. Proceedings of the 32nd International Colloquium on Automata, Languages and Programming. ICALP, 2005.

KLEIN, M. V. Identificação do nível de relacionamento entre a claro digital e seus clientes corporativos. 2003. Dissertação (Mestrado em Administração). Universidade Federal do Rio Grande do Sul. Porto Alegre, 2003.

KOTLER, P.; KELLER, K. L. Administração de marketing. 12 ed. São Paulo: Pearson Prentice Hall, 2006.

KOUBAA, Y. Country of origin, brand image perception and brand image structure. Asia Pacific Journal of Marketing and Logistics, v. 20, n. 2, p. 139-155, 2008.

LEMOS, C. Inovação na era do conhecimento. In: LASTRES, H.; ALBAGLI, S. Informação e globalização na era do conhecimento. Rio de Janeiro: Campus, 1999.

MANUAL DE OSLO: Diretrizes para a coleta e interpretação de dados sobre inovação. OCDE Ministério da Ciência e Tecnologia. $3^{a}$.ed., 2005. Disponível em:

<http://www.mct.gov.br/index.php/content/view/44912.html>. Acesso em: 13/11/2009.

REAd I Porto Alegre - Edição 75 - N 2 - maio/agosto 2013 - p. 401-432 
Celso Augusto Rimoli, Léo Eduardo Pastori Noronha \& Francisco Antonio Serralvo

MARIANO, S. Gestão da inovação: Uma Abordagem Integrada. Relatório técnico. Universidade Federal Fluminense, 2004.

MATTHIESEN, I.; PHAU, I.; Brand image inconsistencies of luxury fashion brands. Journal of Fashion Marketing and Management, v. 14, n. 2, p. 202-218, 2010.

MOHR, J.; SENGUPTA, S. SLATER, S. Marketing of high technology products and innovations. 2.ed. New Jersey: Pearson, 2005.

MOREIRA, D.; QUEIROZ, A. C. Inovação: conceitos fundamentais. In: MOREIRA, D.; QUEIROZ, A. (Orgs.). Inovação Organizacional e Tecnológica. São Paulo: Thomson, 2007.

NUNES, G.; HAIGH, D. Marca: valor do intangível. São Paulo: Atlas, 2003.

OZCAN, K. Consumer-to-Consumer interactions in a networked society: Word-OfMouth Theory, Consumer Experiences, and Network Dynamics. University of Michigan United States. Michigan, Ago, 2004.

PIORE, M.; SOBEL, C. F. The second industrial divide possibilities for prosperity. Nova York: Basic Books, 1984.

PUTNAN, R. D. Comunidade e democracia: A experiência da Itália Moderna. Rio de Janeiro: Fundação Getúlio Vargas, 1996.

RAJAGOPAL. Branding paradigm for the bottom of the pyramid markets. Measuring Business Excellence, v. 13, n. 4, p. 58-68, 2009.

RIMOLI, C. A.; GIGLIO, E. M. Contribuição das teorias de redes e de inovação para marketing. In: Anais do XXXIII Encontro da ANPAD, São Paulo, ANPAD, 2009.

RINDELL, A.; STRANDVIK, T. Corporate brand evolution: corporate brand images involving in consumers' every day life. European Business Review, v. 22, n. 3, p. 276-286, 2010 . 
Aspectos de inovação e de redes que afetam a imagem da marca: o caso Harley-Davidson e Buell

RUÃO, T.; FARHANGMER, M. A Imagem da marca: Análise das funções de representação e apelo no marketing das marcas. Um Estudo de Caso. Actas do I Seminário de Marketing Estratégico e Planejamento. Escola de Economia e Gestão, Universidade do Minho, Portugal. 2000.

SALANCIK, G. R. Wanted: a good network theory of organization. Administrative Science Quarterly, v. 40, n. 2, p. 345-349, 1995.

SEGUELA, J. Hollywood lave plus blanc. France: Flammarion, 1982.

TICHY, N.; TUSHMAN, M.; FOMBRUN, C. Social networks analysis for organizations. Academy of Management Review, v. 4, n. 4, p. 507-519, 1979.

UZZI, B. Social structure and competition in interfirm networks: the paradox of embeddedness. Administrative Science Quarterly, v. 42, n. 1, p. 35-67, mar. 1997.

YIN, Robert K. Estudo de caso: planejamento e métodos. 3. ed. Porto Alegre: Bookman, 2005. 